\title{
Prognostic role of traditional cardiovascular risk factors in patients with idiopathic pulmonary arterial hypertension
}

\author{
Serdar Kalemci', Aydın Sarıhan², Arife Zeybek ${ }^{3}$, Nihat Taşdemir ${ }^{4}$
}

\author{
${ }^{1}$ Department of Chest Diseases, Medical Park Gebze Hospital, Kocaeli, Turkey \\ ${ }^{2}$ Manisa State Hospital, Manisa, Turkey \\ ${ }^{3}$ Department of Chest Surgery, School of Medicine, Muğla Sıtkı Koçman University, Muğla, \\ Turkey \\ ${ }^{4}$ Department of Radiology, Medical Park Gebze Hospital, Kocaeli, Turkey
}

Submitted: 22 April 2019

Accepted: 14 June 2019

Arch Med Sci 2020; 16 (6): 1459-1460

DOI: https://doi.org/10.5114/aoms.2019.91209

Copyright @ 2019 Termedia \& Banach

We have read with great interest the article recently published by Jonas et al. entitled "Prognostic role of traditional cardiovascular risk factors in patients with idiopathic pulmonary arterial hypertension" [1]. In this study we would like to draw attention to some important points.

The authors have shown a possible relationship between the lifespan and severity of the disease and alterations in glucose metabolism and lipid profiles in patients with idiopathic pulmonary arterial hypertension (IPAH). Selective serotonin reuptake inhibitors (SSRI) are worldwide prescribed anti-depressant drugs and they increase the risk of cardiovascular diseases [2, 3]. A recent report has shown that use of SSRI definitely induces pulmonary artery hypertension [4]. However, in this present study, we did not see any information related to the use of SSRI in patients with IPAH and control subjects. Amphetamines, which increase dopamine concentration by inhibiting dopamine reuptake in neuronal synapses, are widely used for treatment of attention-deficit disorders, obesity and narcolepsy $[4,5]$. However, abuse of these drugs is also increasing around the world. It is well documented that amphetamines significantly increase the risk of cardiovascular diseases [6]. The authors have never mentioned the drug use between the groups. We suggest that use of SSRIs and amphetamines should be questioned in patients with IPAH.

\section{Conflict of interest}

The authors declare no conflict of interest.

\section{References}

1. Jonas K, Waligóra M, Magoń W, et al. Prognostic role of traditional cardiovascular risk factors in patients with idiopathic pulmonary arterial hypertension. Arch Med Sci 2019; 15: 1397-1406.

2. Biffi A, Scotti L, Corrao G. Use of antidepressants and the risk of cardiovascular and cerebrovascular disease: a meta-analysis of observational studies. Eur J Clin Pharmacol 2017; 73: 487-97.

3. Visco DB, Manhães-de-Castro R, Chaves WF, et al. Selective serotonin reuptake inhibitors affect structure, function and metabolism of skeletal muscle: a systematic review. Pharmacol Res 2018; 136: 194-204.

\author{
Corresponding author: \\ Aydın Sarıhan MD \\ Manisa City Hospital \\ Adnan Menderes Mh. 132. \\ Sokak No: 15 \\ 45020 Manisa, Turkey \\ Phone: +90 5448777117 \\ E-mail: aydinsarihan@ \\ yahoo.com
}


4. Garg L, Akbar G, Agrawal S, et al. Drug-induced pulmonary arterial hypertension: a review. Heart Fail Rev 2017; 22: 289-97.

5. Zhang M, Lv D, Zhou W, et al. The levels of triglyceride and total cholesterol in methamphetamine dependence. Medicine 2017; 96: e6631.

6. Paratz ED, Cunningham NJ, Maclsaac Al. The cardiac complications of methamphetamines. Heart Lung Circ 2016; 25: 325-32. 